\title{
Influence of Wear and Tool Geometry on the Chatter, Cutting Force, and Surface Integrity of TB6 Titanium Alloy with Solid Carbide Cutters of Different Geometry
}

\author{
Jianyong Liu1 - Jianfei Sun²,3,4 - Uzair Khaleeq uz Zaman $5,{ }^{*}$ - Wuyi Chen ${ }^{2,3}$ \\ 1 AECC Shenyang Liming Aero-Engine Co., Ltd., China \\ 2 Beihang University, School of Mechanical Engineering and Automation, China \\ ${ }^{3}$ Collaborative Innovation Center of Advanced Aero-Engine, China \\ ${ }^{4}$ Beijing Engineering Technological Research Center of High-efficient \& Green CNC Machining Process and Equipment, China \\ ${ }^{5}$ National University of Sciences and Technology, College of Electrical and Mechanical Engineering, Pakistan
}

In this paper, vibration-free milling cutters (variable helix (VH) and variable pitch (VP) end mills) and standard (SD) end mills are used to machine TB6 (Ti-10V-2Fe-3Al) titanium alloy in order to study the influence of wear and geometric structure parameters of milling cutters on chatter, cutting force and surface integrity of machined surfaces. The results of the tests show that the wear of milling cutters has a significant influence on the chatter, cutting force, roughness, residual stress, and microhardness. Geometric structure parameters of milling cutters also have a clear impact on both chatter and cutting force. Also, chatter and cutting force have significant effects on roughness and residual stress, which are in turn affected by tool geometric structure parameters, separately.

Keywords: chatter, cutting force, surface integrity, TB6 Titanium alloy, wear

\section{Highlights}

- An analysis was performed to study the effects of wear, chatter, and cutting force on the surface integrity of TB6 titanium alloy when machined with solid carbide cutters of different geometry.

- Surface integrity has an important influence on surface quality and is influenced by many factors, such as vibration, cutting parameters, tool wear and tool geometric structure parameters.

- As per experimental results, the wear of milling cutters has a significant influence on the chatter, cutting force, roughness, residual stress, and microhardness.

- Chatter and cutting force have significant effects on roughness and residual stress.

\section{INTRODUCTION}

Titanium alloy has been widely used in various fields, such as aerospace, automotive, medical equipment, etc., because of its underlying properties, including high specific strength, excellent corrosion resistance, and good fatigue resistance [1] and [2]. TB6 titanium alloy is a near $\beta$ phase titanium alloy, which is denser and presents high strength at low operating temperatures [3]. TB6 titanium alloy is primarily used in aircraft structural components (aircraft fuselage, wing, landing gear, and helicopter rotor parts) [4]. However, some characteristics of TB6 titanium alloy, such as low thermal conductivity, low elastic modulus, and high chemical activity, can cause high cutting temperatures, large cutting forces, shorter tool life, low metal removal rates, and poor work surface integrity [5] and [6]. The improvement of surface integrity of TB6 titanium is, therefore, a challengeable subject in the area of manufacturing due to its low machinability.

Surface integrity is commonly defined as "the topographical, mechanical, chemical and metallurgical state of a machined surface and its relationship to functional performance [7]. It consists of factors such as surface roughness, work hardening, residual stress, microstructure, etc. Moreover, surface integrity is an important performance characteristic of the machined surface quality, thereby determining the functionality and fatigue life of the critical structure components [8]. Surface integrity is impacted by many factors, including vibration, cutting force, tool wear, and similar. Pimenov et al. [9] studied the effect of the relative position on machined surface roughness with a face-milling cutter. The results proved that the relative position of the milling cutter and workpiece affected the cutting force, vibration and, surface roughness.

In 1907, chatter, as a machining phenomenon, was first introduced by [10], after which it has been extensively studied [11]. The chatter during machining has a significant effect on surface integrity, tool wear, machine damage, etc. It can not only reduce the surface quality of the workpiece and increase tool wear but can also cause damage to the machine [12]. Several methods have been used in the literature 
to reduce vibration in the cutting process, and the most widely used technique is to optimize cutting conditions based on the stability lobe diagram [13] and [14]. Since the cutting parameters are restricted by the stability lobe diagram, only cutting parameters within a particular range can effectively suppress chatter. Reducing the spindle speed will reduce vibration but at the cost of lower material removal rate and a decrease in machining efficiency. If the cutting speed is increased, the cutting temperature will also increase, thereby affecting the surface quality and tool wear because of high chemical activity and low thermal conductivity of TB6 titanium alloy. Furthermore, the variable helix (VH) and variable pitch (VP) milling cutters can effectively suppress chatter at low cutting speeds [15] and [16] making their use an economical method to reduce the vibration and improve the cutting stability without changing the cutting speed by using the vibration-free milling cutters.

Many researchers have indicated that the geometric structure parameters of milling cutters had significant influence on the quality of machined surfaces. Particularly when the variable helix (VH) and variable pitch (VP) tools were involved, the investigations were usually carried out to enhance stability and suppress regenerative chatter in order to improve the milling quality. Ott et al. [17] studied the mechanical vibrations in milling with non-uniform pitch and variable helix tools. The results showed that the distributed delay in variable helix tools led to a stabilization of the cutting process. Moreover, Sims et al. [18] analysed the influence of radial immersion on the stability of variable pitch or helix milling tools. The cyclic fold bifurcations were found to exist for both at lower radial immersions. Also, Wang et al. [19] investigated the chatter prediction for variable pitch and variable helix milling and found them to be effective for suppressing chatter. Stability lobes were studied by Altintas et al. [20] for variable pitch milling cutters and designed an optimal tooth spacing to increase the chatter-free depth of cuts. Li et al. [21] also investigated the effect of a face-milling cutter with a variable pitch on vibration. Furthermore, Niu et al. [22] improved the generalized Runge-Kutta method by considering runout to analyse the milling process stability with variable pitch and variable helix milling cutters.

However, the published literature on the $\mathrm{VH}$ and VP milling cutters seldom analysed the chatter with tool wear and rarely emphasized surface quality indexes other than chatter induced surface texture.

Furthermore, cutting forces have a great influence on workpiece precision, surface quality, cutting system vibration, cutting power, and tool life, especially when the milling cutters have a complex geometry in machining [23]. Cutting forces are affected by several factors such as tool geometry, workpiece material properties, cutting conditions, etc. [24]. Huang et al. [25] investigated the cutting forces by analysing the time domain and the frequency domain in TC4 titanium alloy milling. The results showed that the radial forces of VP milling cutter were minimum compared with standard (SD) and VH milling cutters.

Moreover, tool wear has a significant impact on the surface integrity of titanium alloy. The influence of tool wear on roughness is related to the tool wear state. Liang and Liu [26] investigated the effect of tool flank wear on surface integrity; the results showed that the roughness first increased and then decreased with the tool flank wear increasing from $0 \mathrm{~mm}$ to $0.3 \mathrm{~mm}$. This behaviour was caused by different wear states of tool flank face. However, Yang et al. [27] reported contradictory results, in which the machined surface roughness of TB6 presented an increasing trend with the increase of tool flank wear. Tool wear also had significant influence on residual stress and microhardness. Residual stresses beneath the machined surface became much more compressive and penetrated to a deeper depth with the worn tools [28]. Nevertheless, some other researchers obtained the contrary results, with the tool flank wear increasing, and the surface residual stresses becoming more tensile due to the increased temperature [29]. The hardness of the machined surfaces produced with worn tools was harder, and the affected layer depth was larger than those produced with new tools under the same cutting parameters [30] and [31].

Consequently, based on the literature reviewed, the reasons affecting the surface integrity of titanium alloy are complex, and a gap in research exists about the influence of wear, chatter, and cutting force on surface integrity with vibration-free milling cutters. The study in this paper investigates the surface integrity of the titanium alloy TB6 machined by VH, VP, and SD milling cutters, and aims to provide reference data for the effects of wear, tool geometric structure parameter, chatter, and cutting force on surface integrity.

\section{EXPERIMENTAL DESIGN}

Tool wear and surface integrity tests were designed for the subject purpose. First, a wear test was carried out to observe the flank wear of the milling cutters. Then the cutting test of surface integrity was carried out after the flank wear of the three types of milling 
cutters reached the blunt standard. Cutting force and vibration were recorded during the surface integrity test.

VH, VP, and SD milling cutters were used in the cutting tests of wear and surface integrity. K44UF cemented carbide was used as tool material for the three types of milling cutters, which were not coated. The geometric structure parameters of the three types of milling cutters are shown in Table 1.

Table 1. Geometric structure parameters of three types of milling cutters

\begin{tabular}{ccccc}
\hline $\begin{array}{c}\text { Milling } \\
\text { cutter }\end{array}$ & $\begin{array}{c}\text { No. of } \\
\text { flutes }\end{array}$ & $\begin{array}{c}\text { Radius of } \\
\text { tool [mm] }\end{array}$ & $\begin{array}{c}\text { Helix } \\
\text { angle [deg] }\end{array}$ & $\begin{array}{c}\text { Tooth } \\
\text { pitch [deg] }\end{array}$ \\
\hline VP & 4 & 5 & 45 & 86 and 94 \\
\hline VH & 4 & 5 & 41 and 45 & 85 and 95 \\
\hline SD & 4 & 5 & 45 & 90 \\
\hline
\end{tabular}

The three types of milling cutters had the same geometric structure parameters except for the helix angle and tooth pitch. The cross-section of three types of milling cutters is shown in Fig. 1.
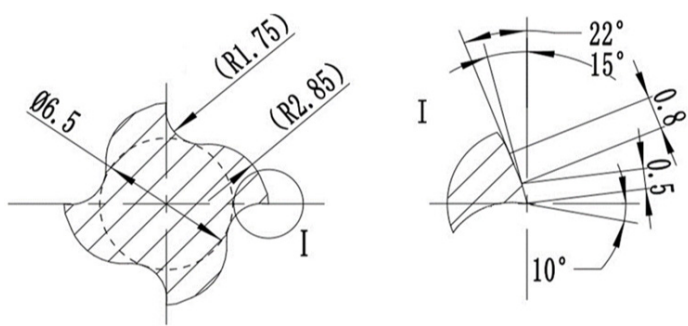

Fig. 1. Cross-section of three types of milling cutters; the lengths are in $\mathrm{mm}$

The two cutting tests were then carried out under dry milling conditions, and the workpieces were machined by side milling and up milling. The size of workpiece used in the two cutting tests was $(70 \times$ $57.5 \times 35) \mathrm{mm}$. The workpiece was machined with an NC machine tool of type BV75. The material of the workpiece used in all tests was TB6 titanium alloy, which is one of the $\beta$-phase titanium alloys with high strength, high toughness, and machined after the forging process. The nominal chemical composition of TB6 titanium alloy is shown in Table 2, and the mechanical properties at room temperature of the TB6 alloy are shown in Table 3 [32].

Wear of the milling cutters was observed using the Dino-Lite AM7013MZT microscope and expressed by the width of flank wear of milling cutters. The blunt standards of the three types of milling cutters were $0.1 \mathrm{~mm}, 0.2 \mathrm{~mm}$, and $0.3 \mathrm{~mm}$, respectively. The width of flank (the main cutting edge) wear of milling cutters was measured when the wear of cutting edge was close to the blunt standard. Then the mean value of four cutting edges was taken as the wear extent of the milling cutter.

Table 2. Chemical composition of TB6 (mass fraction, \%)

\begin{tabular}{|c|c|c|c|}
\hline Element & wt. [\%] & Element & wt. [\%] \\
\hline $\mathrm{Al}$ & 3.15 & 0 & 0.10 \\
\hline V & 10.5 & $\mathrm{~N}$ & 0.03 \\
\hline $\mathrm{Fe}$ & 2.1 & $\mathrm{H}$ & 0.002 \\
\hline C & 0.02 & $\mathrm{Ti}$ & Balance \\
\hline
\end{tabular}

Table 3. Mechanical properties of TB6 at room temperature

\begin{tabular}{lc}
\hline Mechanical properties & Value \\
\hline Tensile strength [MPa] & 1105 \\
\hline Yield strength [MPa] & 1035 \\
\hline Elastic modulus [GPa] & 106 \\
\hline Elongation [\%] & $4 \sim 10$ \\
\hline Hardness [HV] & $>375$ \\
\hline Fracture toughness [MPa $\sqrt{ } \mathrm{m}]$ & $\geq 60$ \\
\hline
\end{tabular}

Cutting force was measured with a piezoelectric force sensor of type CL-YD-3310, and the acceleration was measured with a piezoelectric acceleration transducer of type VM45-1QZH. The radial rigidity of milling cutter was low, and since the radial cutting force was more suitable for analysing the vibration of the cutting system than the tangential and axial cutting forces [33] and [34], it was studied in this paper. The vibration and cutting force measurement devices of the low rigidity cutting test are shown in Fig. 2. Furthermore, the modes of the cutting system were measured with hammering tests. The first-order modes of these two test systems are shown in Table 4.

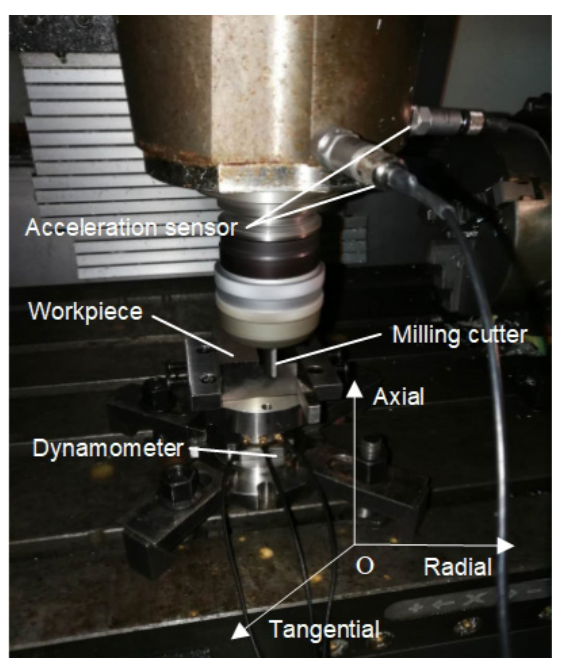

Fig. 2. Measuring equipment of vibration and cutting force of low rigidity cutting test 
Table 4. First-order modes of cutting systems

\begin{tabular}{ccc}
\hline $\begin{array}{c}\text { Cutting } \\
\text { system }\end{array}$ & $\begin{array}{c}\text { Workpiece-dynamometer- } \\
\text { worktable }[\mathrm{Hz}]\end{array}$ & Tool-spindle $[\mathrm{Hz}]$ \\
\hline Mode & 469 & 216 \\
\hline
\end{tabular}

During the cutting process, the depth of cut and the width of cut were kept constant, and the overhang of the three types of milling cutters was $40 \mathrm{~mm}$ each. The cutting parameters used in the two cutting tests are shown in Table 5.

Table 5. Cutting parameters of wear and surface integrity cutting tests

\begin{tabular}{|c|c|c|c|c|c|}
\hline $\begin{array}{l}\text { Test } \\
\text { no. }\end{array}$ & $\begin{array}{c}\text { Cutting speed } \\
{[\mathrm{m} / \mathrm{min}]}\end{array}$ & $\begin{array}{c}\text { Feed per } \\
\text { tooth }[\mathrm{mm} / \mathrm{z}]\end{array}$ & $\begin{array}{l}\text { Depth of } \\
\text { cut [mm] }\end{array}$ & $\begin{array}{l}\text { Width of } \\
\text { cut [mm] }\end{array}$ & $\begin{array}{l}\text { Milling } \\
\text { cutter }\end{array}$ \\
\hline 1 & 30 & 0.06 & 5 & 0.5 & \multirow{3}{*}{ SD } \\
\hline 2 & 30 & 0.06 & 5 & 0.5 & \\
\hline 3 & 30 & 0.06 & 5 & 0.5 & \\
\hline 4 & 30 & 0.06 & 5 & 0.5 & \multirow{3}{*}{ VH } \\
\hline 5 & 30 & 0.06 & 5 & 0.5 & \\
\hline 6 & 30 & 0.06 & 5 & 0.5 & \\
\hline 7 & 30 & 0.06 & 5 & 0.5 & \multirow{3}{*}{ VP } \\
\hline 8 & 30 & 0.06 & 5 & 0.5 & \\
\hline 9 & 30 & 0.06 & 5 & 0.5 & \\
\hline
\end{tabular}

Surface roughness was measured by using the roughness measuring instrument of type TIME3220. The roughness of the workpiece surface was measured along the feed direction. The sampling length of roughness measurement was $0.8 \mathrm{~mm}$, and the evaluation length was $4 \mathrm{~mm}$. Samples were cleaned using ethanol solution via ultrasonic cleaning before taking measurements. Nine samples were measured in this experiment, and the average roughness was obtained by measuring roughness five times for each sample.

The residual stress was measured with the Prism system, produced by Stresstech Oy. The hole-drilling technique was used for residual stress measurement in which, by removing a volume of material, residual stresses were released locally, and the stress equilibrium in the part was changed. The stresses in the remaining material rebalanced and the surface distorted slightly, especially near the hole. The Prism system measured surface distortion optically using a laser that was diffusely reflected from the sample surface.

For the nine samples measured, the distances below the surface where the holes were drilled were $0.01 \mathrm{~mm}, 0.02 \mathrm{~mm}, 0.03 \mathrm{~mm}, 0.04 \mathrm{~mm}, 0.05 \mathrm{~mm}$, $0.060 \mathrm{~mm}, 0.07 \mathrm{~mm}$ and $0.080 \mathrm{~mm}$.
Nano-hardness at different depths on the crosssection of the machined surface was measured using a Nano Indentationer G200 system. Nine tests were performed to obtain the nano hardness. The three indentations performed below the machined surface in each test were $5 \mu \mathrm{m}, 50 \mu \mathrm{m}$, and $100 \mu \mathrm{m}$, respectively (as shown in Fig. 3). The penetration depths were realized using diamond Berkovich tip after precise focus on the cross-section. The penetration depths for each indentation below the surface were $1 \mu \mathrm{m}$.

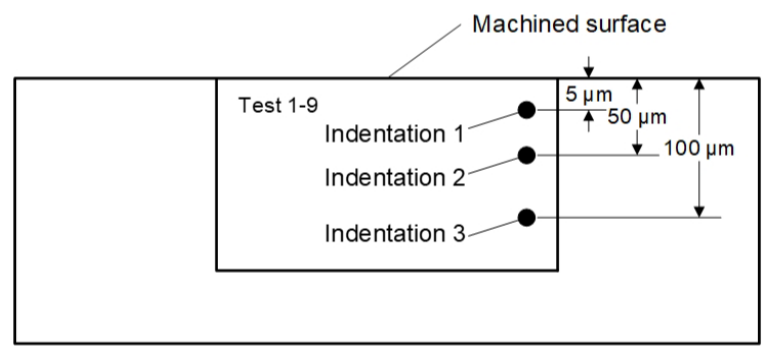

Fig. 3. Distribution of indentations in nanometer indentation measurement

Microstructures were observed by using the threedimensional (3D) laser microscope LEXT OLS4100. First, the nine samples were embedded to three specimens, and each specimen included three samples. Then, the samples were abraded and polished. Finally, the samples were etched for about 20 seconds using a corrodent matched by $\mathrm{HF}: \mathrm{HNO} 3: \mathrm{H} 2 \mathrm{O}=1: 4: 45$.

\section{RESULTS AND DISCUSSION}

\subsection{Wear}

The wear extents were determined by measuring the flank wear of the VH, VP, and SD milling cutters. First, the flank wear of each cutting edge of the three types of milling cutters was measured for five times and the average of the wear of the four cutting edges was taken to obtain the wear extent of each milling cutter. The blunt standard of the three types of milling cutters was the same for all, and the blunt standard was $0.1 \mathrm{~mm}, 0.2 \mathrm{~mm}$, and $0.3 \mathrm{~mm}$. When cutting speed was set to $30 \mathrm{~m} / \mathrm{min}$, and the feed was fixed at 0.06 $\mathrm{mm}$, the wear extent of each milling cutter changed with time; the changes observed are shown in Fig. 4.

It can be deduced from Fig. 4 that the wear of $\mathrm{VH}, \mathrm{VP}$, and SD milling cutters was at the normal wear stage. When the wear extents were close to 0.1 $\mathrm{mm}, 0.2 \mathrm{~mm}$, and $0.3 \mathrm{~mm}$, the wear of VP milling cutter was the fastest, followed by VH milling cutter, and SD milling cutter. Therefore, SD milling cutter 


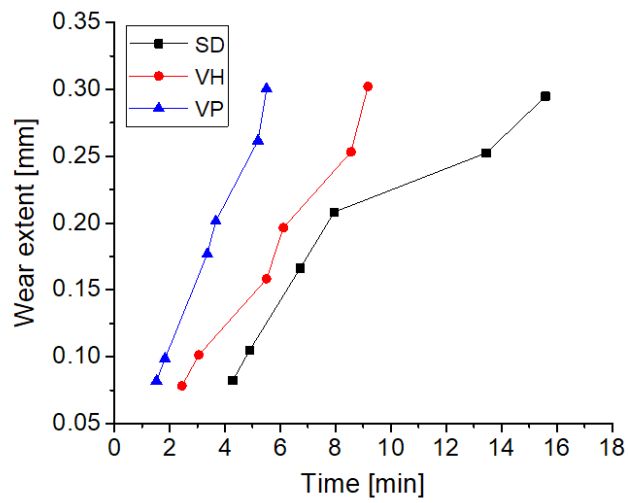

Fig. 4. Wear extent varied with time of three types of milling cutters has the best wear resistance, and the VP milling cutter has the worst wear resistance.

As shown in Fig. 5, when the wear of milling cutter was close to the blunt standard, which was 0.1 $\mathrm{mm}$ or $0.2 \mathrm{~mm}$, the wear measuring errors of teeth of VP and VH milling cutters were big and that of SD milling cutter were small. This phenomenon is due to the changes of helix and pitch causing noneven wear of teeth of vibration-free milling cutters, thereby increasing the wear measuring errors. With the increase of wear, the wear-measuring errors of $\mathrm{VP}$ and $\mathrm{VH}$ milling cutter edges had a decreasing tendency, especially when the wear was close to the blunt standard of $0.3 \mathrm{~mm}$. Also, the wear measuring
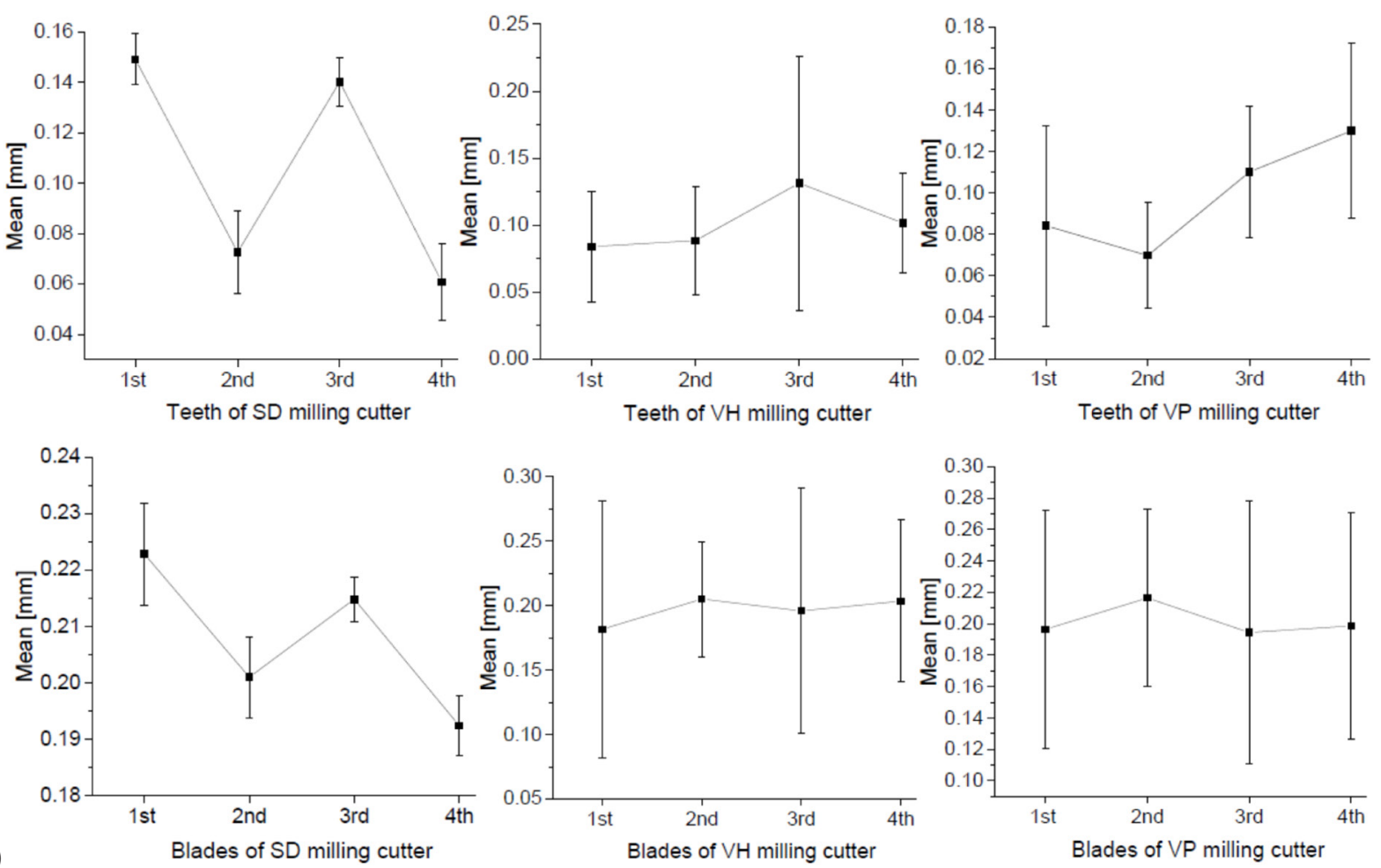

b)
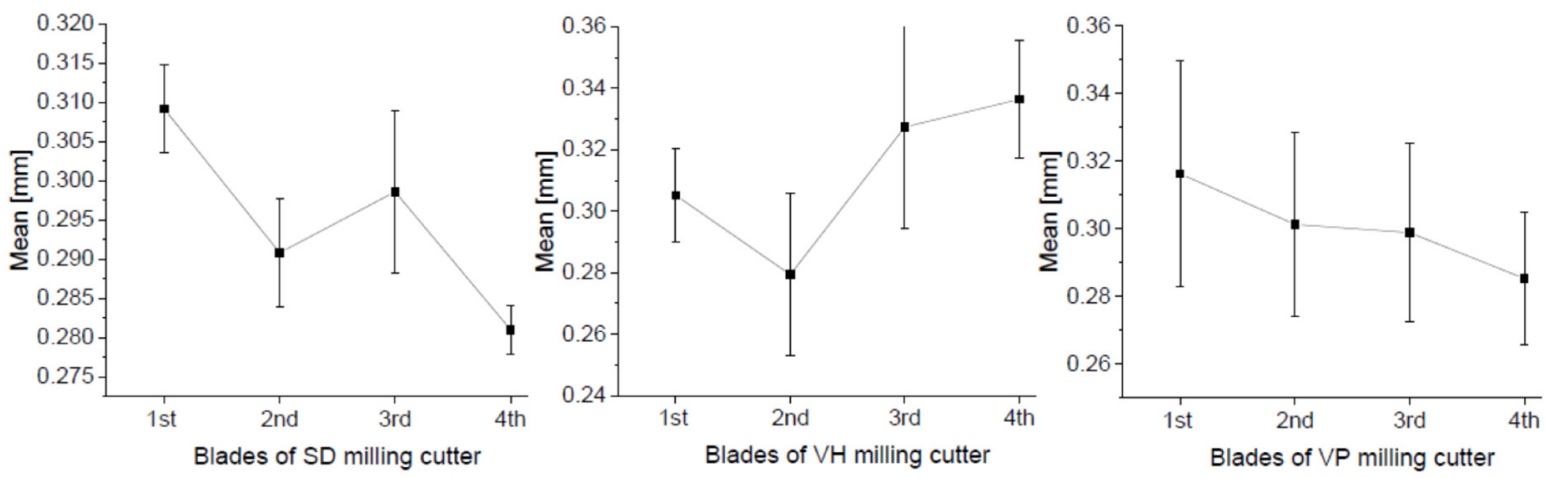

Fig. 5. Wear measuring errors of teeth of three types of milling cutters; a) $V B=0.1 \mathrm{~mm}, b) V B=0.2 \mathrm{~mm}$, and c) $V B=0.3 \mathrm{~mm}$ 
errors of VP and VH milling cutter edges decreased significantly, thereby causing reductions in the nonuniform wear caused by the cutter geometry (helix angle and pitch).

The wear-measuring errors of the three types of milling cutters are shown in Table 6 , which shows that the error between the measured wear of the three types of milling cutters and the blunt standard was between $0.1 \%$ and $5.1 \%$, and the measured wear was close to the blunt standard.

Table 6. Measuring errors of wear

\begin{tabular}{ccccc}
\hline $\begin{array}{c}\text { Cutting speed } \\
{[\mathrm{m} / \mathrm{min}]}\end{array}$ & $\begin{array}{c}\text { Blunt standard } \\
{[\mathrm{mm}]}\end{array}$ & $\begin{array}{c}\text { Wear } \\
{[\mathrm{mm}]}\end{array}$ & $\begin{array}{c}\text { Error } \\
{[\%]}\end{array}$ & $\begin{array}{c}\text { Milling } \\
\text { cutter }\end{array}$ \\
\hline \multirow{3}{*}{30} & 0.1 & 0.1048 & 4.8 & \\
\cline { 2 - 4 } & 0.2 & 0.2082 & 4.1 & \multirow{2}{*}{ SD } \\
\cline { 2 - 4 } & 0.3 & 0.2949 & 5.1 & \\
\hline \multirow{3}{*}{30} & 0.1 & 0.1014 & 1.4 & \multirow{2}{*}{ VH } \\
\cline { 2 - 4 } & 0.2 & 0.1965 & 1.75 & \\
\hline \multirow{3}{*}{30} & 0.3 & 0.3121 & 4.03 & \\
\cline { 2 - 4 } & 0.1 & 0.0986 & 1.4 & \multirow{2}{*}{ VP } \\
\cline { 2 - 4 } & 0.2 & 0.2014 & 0.7 & \\
\hline
\end{tabular}

The changes of pitch and helix angles of vibration-free milling cutters induced the cutting force to change, leading to faster wear of $\mathrm{VP}$ and $\mathrm{VH}$ milling cutters compared to wear rate of SD milling cutter. This fact further resulted in even wear of SD milling cutter and non-even wear of VP and VH milling cutter [35] thereby increasing the wear measuring the difficulty of VP and VH milling cutters.

\subsection{Chatter}

\subsubsection{Resonance Analysis}

The vibration frequency is mainly related to the spindle rotation frequency (SRF) and tooth pass frequency (TPF). SRF and TPF are used to analyse whether chatter occurs during the cutting process. $S R F$ is defined as shown in Eq. (1).

$$
S R F=\frac{k n}{60}=\frac{1000 k v}{60 \pi D},
$$

where, $n$ is spindle speed [r/min], $v$ is cutting line speed $[\mathrm{m} / \mathrm{min}], D$ is milling cutter diameter $[\mathrm{mm}]$, and $k$ is the coefficient with values $1,2,3, \ldots$ Moreover, $T P F$ is defined as shown in Eq. (2).

$$
T P F=N \frac{k n}{60},
$$

where, $N$ is the number of teeth of the milling cutter.
According to Eqs. (1) and (2), when the cutting speed was $30 \mathrm{~m} / \mathrm{min}, S R F=15.9 \mathrm{~Hz}$, and $T P F=63.6$ $\mathrm{Hz}$. Moreover, when the occurred frequency was different from multiples of $S R F$ and $T P F$, the chatter appeared.

Figs. 6 to 8 showed the vibration spectrum of $\mathrm{SD}, \mathrm{VH}$ and VP milling cutters when cutting speed was $30 \mathrm{~m} / \mathrm{min}$, the feed was $0.06 \mathrm{~mm}$, and the wear of the three types of milling cutters reached the blunt standard which was $0.1 \mathrm{~mm}, 0.2 \mathrm{~mm}$ and $0.3 \mathrm{~mm}$, respectively. $A^{c} \max$ in these figures represented the maximum chatter amplitude.

The first mode of tool-spindle was $216 \mathrm{~Hz}$, and the first mode of workpiece-dynamometer-worktable was $469 \mathrm{~Hz}$ (see Table 4). Since the maximum amplitude frequency was far from the two modes in the low rigidity cutting test (see Figs. 5 to 7), there was no resonance generation at the frequency of maximum amplitude, but there were amplitudes that had approximate frequency near the two modes, and the amplitudes were small. Therefore, small resonance occurred in the cutting test of surface integrity.

\subsubsection{Influence of Wear on Chatter}

As shown in Fig. 9, the maximum chatter amplitude of $\mathrm{SD}, \mathrm{VH}$ and $\mathrm{VP}$ milling cutters increased with the increase of wear. When the wear extent was 0.1 $\mathrm{mm}$, the chatter of SD milling cutter was the largest, followed by VH milling cutter, and VP milling cutter, and there was a small difference of chatter between the VH and VP milling cutters. When the wear extent was $0.2 \mathrm{~mm}$ and $0.3 \mathrm{~mm}$, the chatter of SD milling cutter was the largest, followed by VP milling cutter, and $\mathrm{VH}$ milling cutter.

\subsection{Cutting Force}

For studying the average cutting force, it can be seen from Fig. 10 that the cutting force of the three types of milling cutters increased when the wear increased from $0.1 \mathrm{~mm}$ to $0.3 \mathrm{~mm}$. When the wear extent was $0.1 \mathrm{~mm}$ and $0.2 \mathrm{~mm}$, the cutting force of VP milling cutter was the largest, followed by SD milling cutter, and $\mathrm{VH}$ milling cutter. When the wear extent was 0.3 $\mathrm{mm}$, the cutting force of SD milling cutter was the largest, followed by VP milling cutter, and VH milling cutter.

The increase of the contact area between the flank face of milling cutter and the workpiece led to the increase of the extrusion pressure. However, due to the different geometric structure parameters of SD, $\mathrm{VH}$, and VP milling cutters, the extrusion pressure 


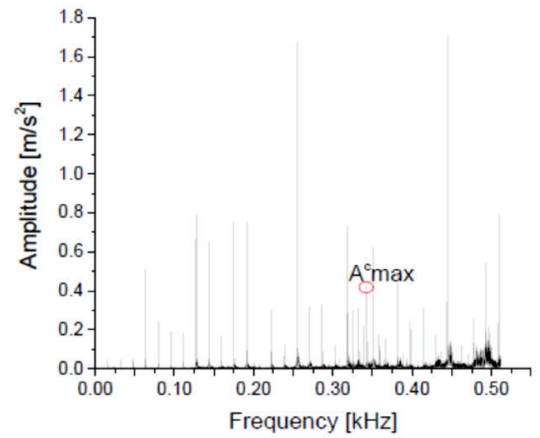

a)

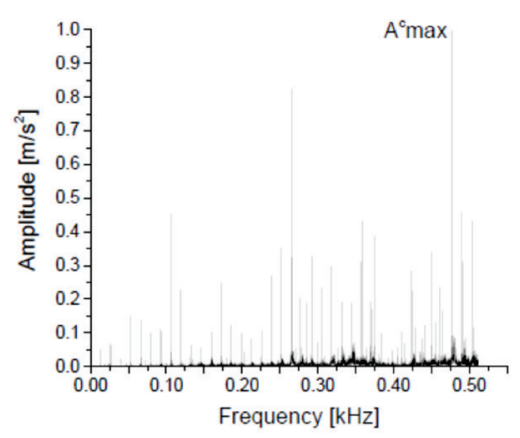

b)

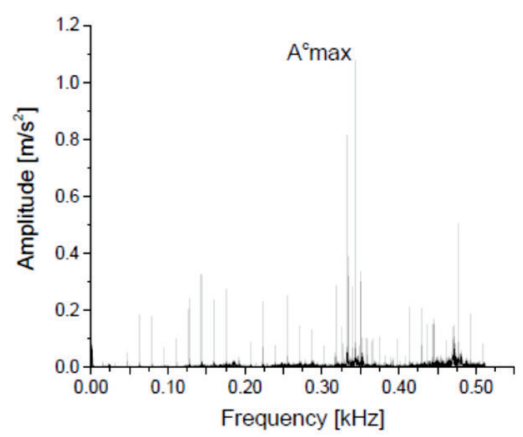

c)

Fig. 6. Acceleration spectrum of standard milling cutter; a) $V B=0.1, V=30 \mathrm{~m} / \mathrm{min}, f=0.06 \mathrm{~mm} / \mathrm{z}$; b) $V B=0.2, V=30 \mathrm{~m} / \mathrm{min}, f=0.06 \mathrm{~mm} / \mathrm{z} ; \mathrm{c}) V B=0.3, V=30 \mathrm{~m} / \mathrm{min}, f=0.06 \mathrm{~mm} / \mathrm{z}$

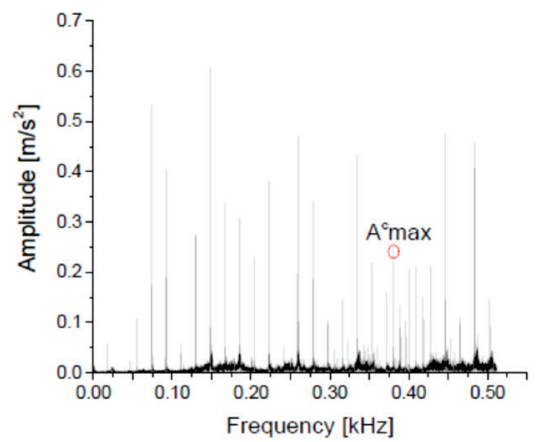

a)

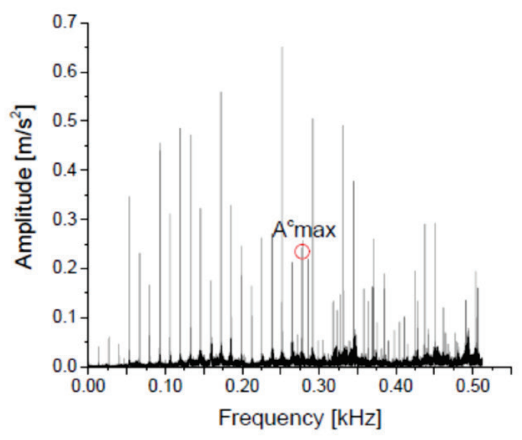

b)

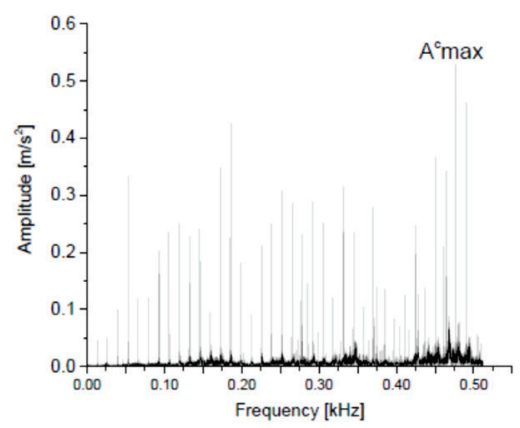

c)

Fig. 7. Acceleration spectrum of variable helix milling cutter a) $V B=0.1, V=30 \mathrm{~m} / \mathrm{min}, f=0.06 \mathrm{~mm} / \mathrm{z}$; b) $V B=0.2, V=30 \mathrm{~m} / \mathrm{min}, f=0.06 \mathrm{~mm} / \mathrm{z} ; \mathrm{c}) V B=0.3, V=30 \mathrm{~m} / \mathrm{min}, f=0.06 \mathrm{~mm} / \mathrm{z}$

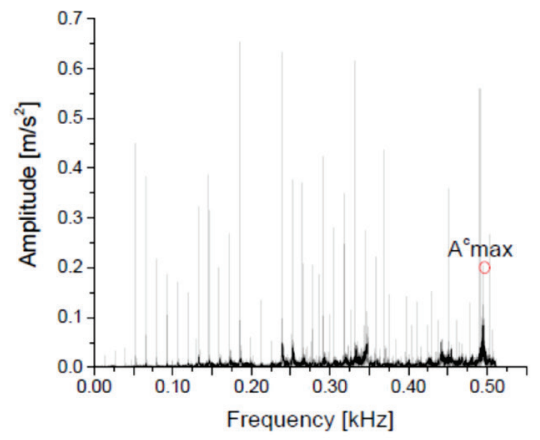

a)

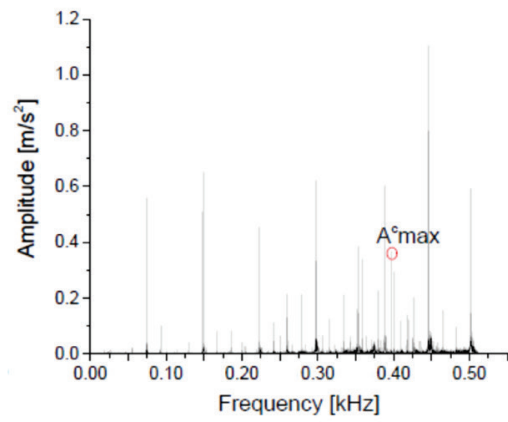

b)

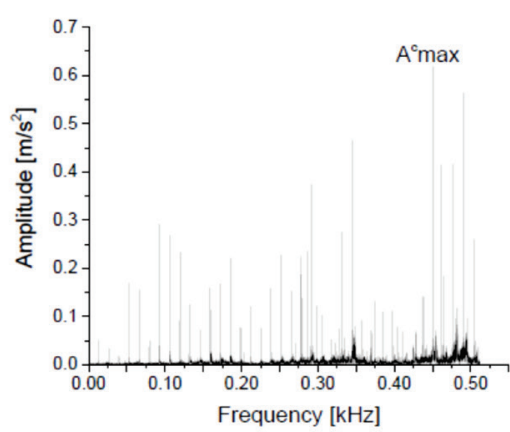

c)

Fig. 8. Acceleration of variable pitch milling cutter a) $V B=0.1, V=30 \mathrm{~m} / \mathrm{min}, f=0.06 \mathrm{~mm} / \mathrm{z}$; b) $V B=0.2, V=30 \mathrm{~m} / \mathrm{min}, f=0.06 \mathrm{~mm} / \mathrm{z} ; \mathrm{c}) V B=0.3, V=30 \mathrm{~m} / \mathrm{min}, f=0.06 \mathrm{~mm} / \mathrm{z}$

was different at the same wear. Compared with SD milling cutter, the actual feed per tooth of VP milling cutter was not consistent, because it was affected by the change of tooth pitch and the superposition of given feed, which also became the reason behind the change in cutting force.

For the VH milling cutter, compared with SD milling cutter, except that the feed of each tooth pitch was inconsistent, which caused the different actual feed, the change of helix angle led to the change of working rake angle, the actual feed and working rake lead subject to change of cutting force. The wear of milling cutter led to the decrease of radial cutting depth which reduced the cutting force. These reasons caused the cutting forces of the three types of milling cutters to turn out to be different. 


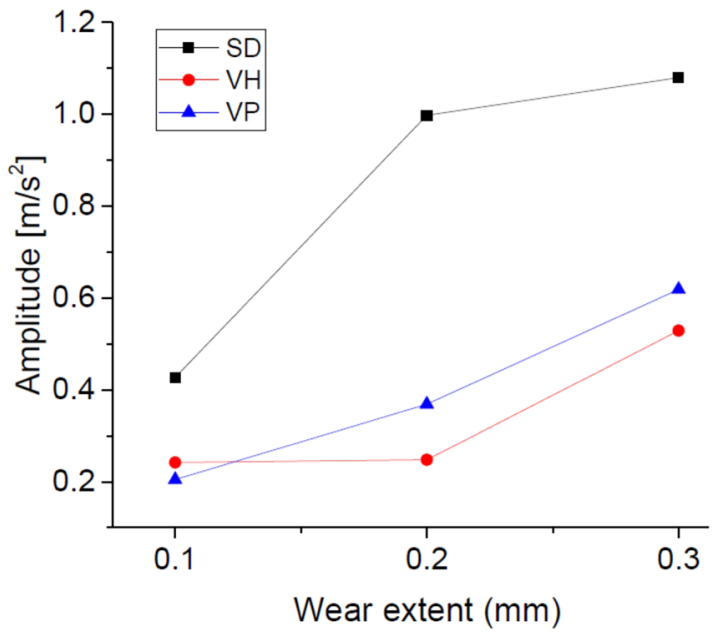

Fig. 9. Chatter varied with wear extent of three types of milling cutters

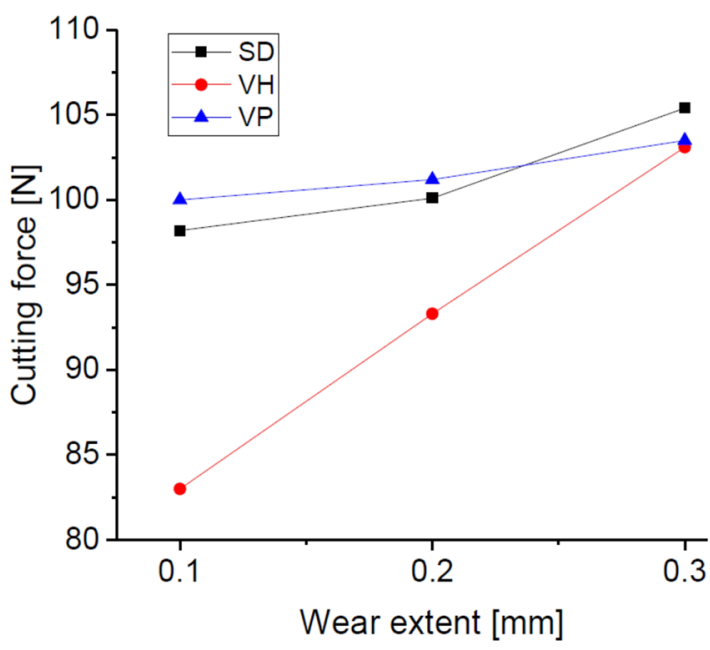

Fig. 10. Cutting force varied with wear extent of three types of milling cutters

\subsection{Surface Integrity}

\subsubsection{Surface Roughness}

\subsubsection{Influence of Wear on Roughness}

The roughness of machined surface produced by $\mathrm{VH}$, VP and SD milling cutters was measured five times, and the mean roughness and standard deviation are shown in Fig. 11. The standard deviations indicated that the discrete degree of measured roughness was small, and the measurement of roughness had high precision.

It can also be seen from Fig. 11 that the roughness of machined surface produced by three types of milling cutters increased with the increase in wear.
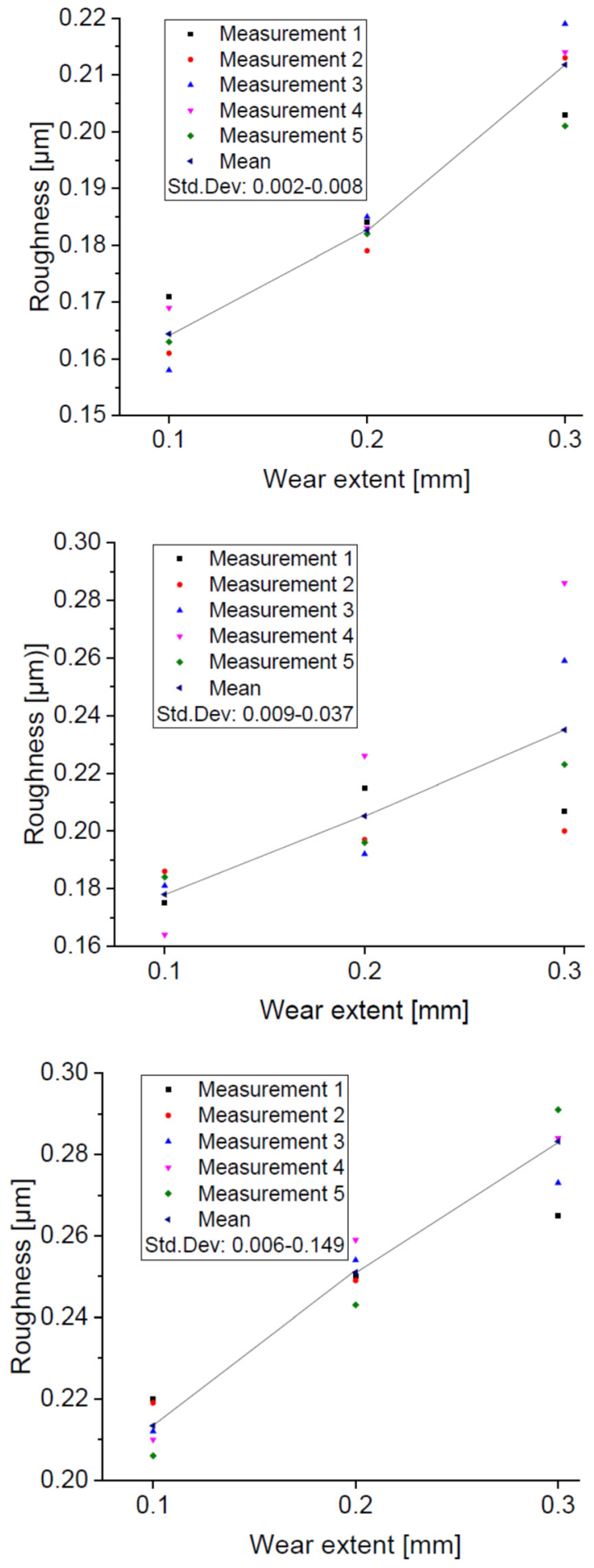

Fig. 11. Roughness of machined surface with three types of milling cutters at different wear, a) VH, b) VP, and c) SD

\subsubsection{Influence of Chatter on Roughness}

Roughness was affected by the chatter. When the roughness produced by $\mathrm{SD}, \mathrm{VH}$, and $\mathrm{VP}$ milling 
cutters were compared (see Fig. 12), the roughness caused by SD milling cutter was the largest, followed by VP milling cutter, and VH milling cutter. The reason for this is that the chatter had a significant influence on roughness. Chatter can increase the radial displacement of the cutter teeth in cutting,

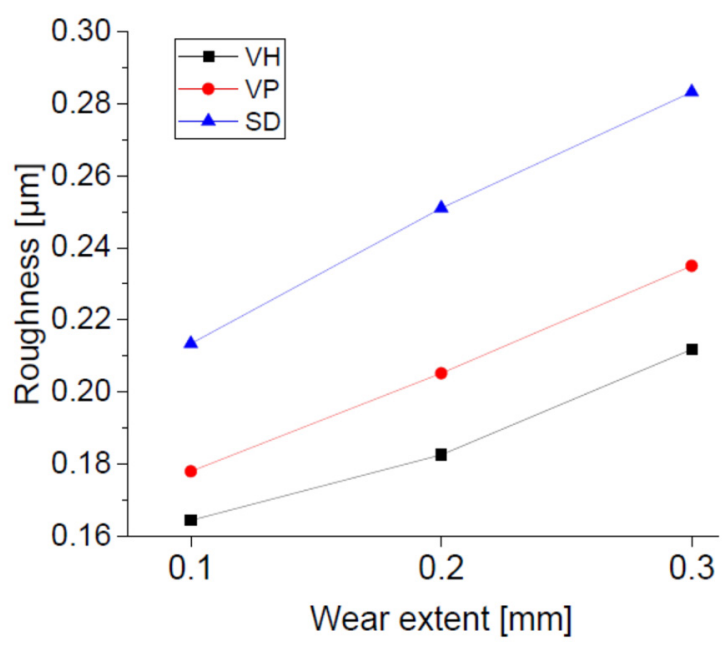

Fig. 12. Influence of geometric structure of milling cutters on surface roughness increasing radial cutting depth, thereby increasing the roughness. Compared with SD milling cutter, when the wear extent was $0.2 \mathrm{~mm}$ and $0.3 \mathrm{~mm}$, the effect of suppressing chatter of $\mathrm{VH}$ milling cutter was the best, followed by VP milling cutter. Although the chatter of the VP milling cutter was the smallest when the wear extent was $0.1 \mathrm{~mm}$, there was little difference of chatter between the VP and the VH milling cutters (as shown in Fig. 9).

The roughness was, therefore, affected not only by the chatter but also by the tool geometric structure parameters. The change of tooth pitch affected the actual feed causing the change of helix angle, which in turn caused the working rake angle, thereby affecting the roughness. For these reasons, the roughness produced by VH milling cutters was the smallest.

\subsubsection{Residual Stress}

The generation process of residual stress is complex. High temperature, pressure, strain, and strain rate are produced in the contact area of milling cutter and workpiece, and uneven elastoplastic deformation occurs in the cutting area. Generally, residual stress is caused by uneven elastoplastic deformation caused

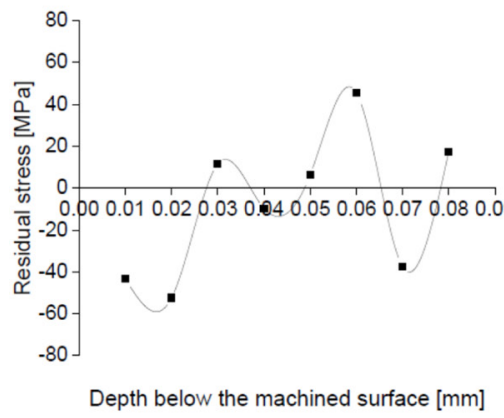

a)

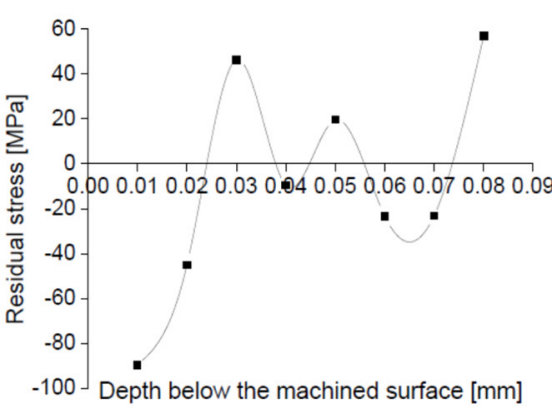

b)

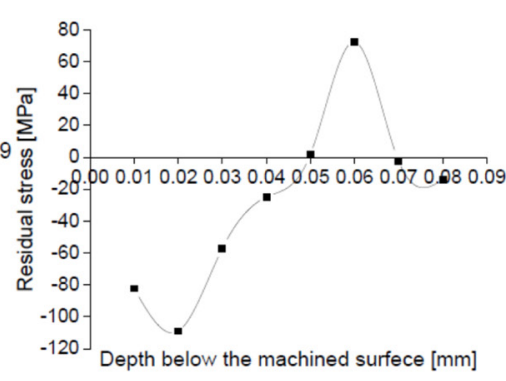

c)

Fig. 13. Residual stress of machined surface with VH milling cutter; a) VB=0.1 mm, b) VB=0.2 $\mathrm{mm}$, and c) VB=0.3 $\mathrm{mm}$

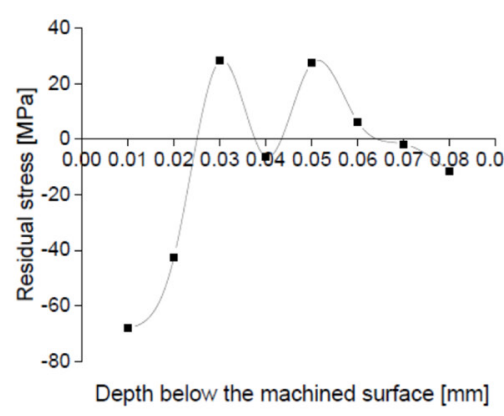

a)

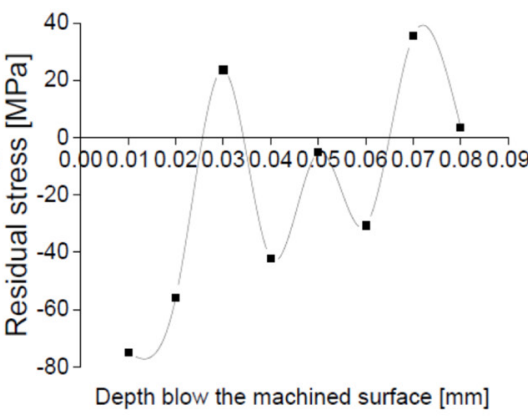

b)

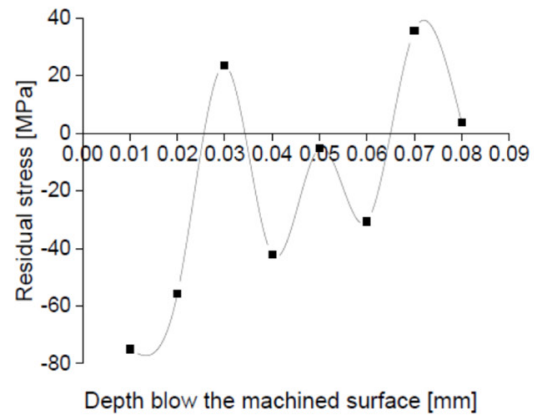

c)

Fig. 14. Residual stress of machined surface with VP milling cutter; a) VB $=0.1 \mathrm{~mm}, b) \mathrm{VB}=0.2 \mathrm{~mm}$, and c) VB=0.3 $\mathrm{mm}$ 
by cutting force and cutting heat. Therefore, residual stress is the result of the interaction of cutting parameters, tool wear, tool geometric structure parameters and several other factors in the cutting process.

In the present work, the resultant residual stresses exhibited irregular distribution (as shown in Figs. 13 to 15). It was found that the residual stress had large fluctuation, which might be caused by the large grain size and uneven plastic deformation of TB6 titanium alloy [36]. It can also be seen that the residual compressive stress tended to be the main stress with the increase of wear.

Moreover, Fig. 16 showed the maximum residual stress of machined surface with VH, VP, and SD milling cutters resulted when the wear extent was 0.1 $\mathrm{mm}$ to $0.3 \mathrm{~mm}$. It can be further observed that the maximum residual tensile stress and the maximum residual compressive stress increased with the increase of wear. When the milling cutter was worn, the contact area between the flank face of milling cutter and the workpiece surface increased, thereby increasing the extrusion pressure on the workpiece, which increased residual compressive stress. At the same time, the wear of milling cutter increased the friction between flank face and the workpiece, causing an increase in the friction heat, thereby causing the increase of residual tensile stress.

The workpiece surface is also affected by both the cutting force and cutting heat in the cutting process, and residual stress is the result of the combined action of the two factors. The depth range of $0 \mathrm{~mm}$ to $0.04 \mathrm{~mm}$ from the machined surface was close to the machined surface of the workpiece. The heat dissipated rapidly in this depth range, and the extrusion effect of cutting force was obvious. Therefore, the residual stress in this depth range was dominated by compressive stress, and the maximum residual compressive stress appeared in this depth range.

Furthermore, the depth range of $0.04 \mathrm{~mm}$ to 0.08 $\mathrm{mm}$ was far from the machined surface. Due to the poor thermal conductivity of TB6 titanium alloy, the thermal stress had an obvious effect on the material in this depth range. Therefore, the residual stress within this depth range was dominated by tensile stress, and the maximum residual tensile stress appeared within this depth range.

\subsubsection{Microhardness}

Nano-hardness was obtained via three steps: loading of sample, dwelling, and unloading. At the start,

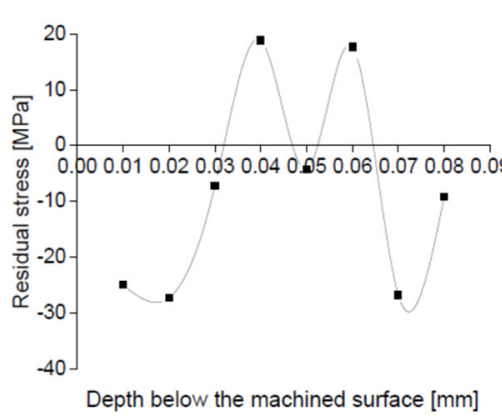

a)

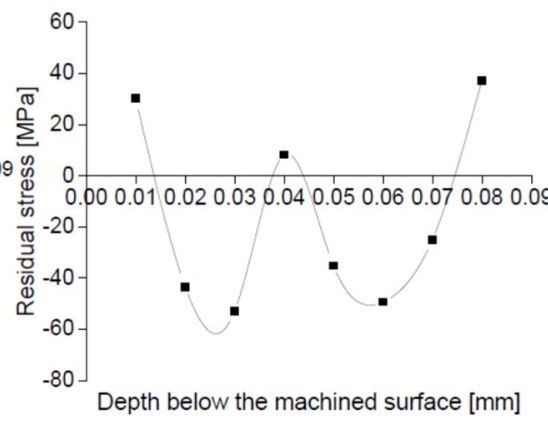

b)

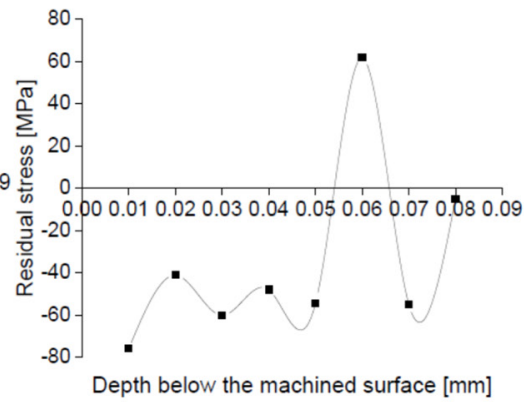

c)

Fig. 15. Residual stress of machined surface with $S D$ milling cutter; a) VB=0.1 mm, b) VB=0.2 mm, and c) VB=0.3 mm

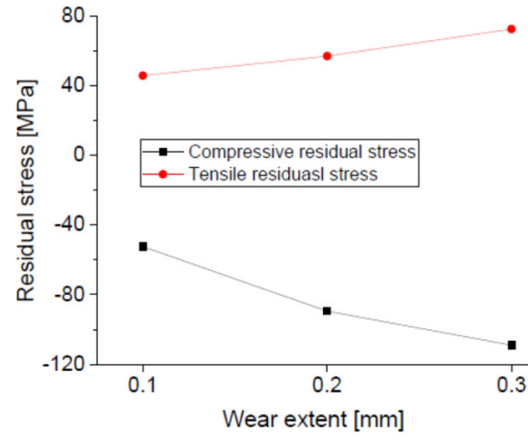

a)

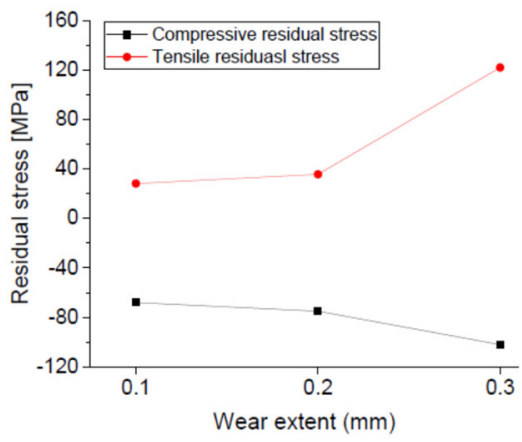

b)

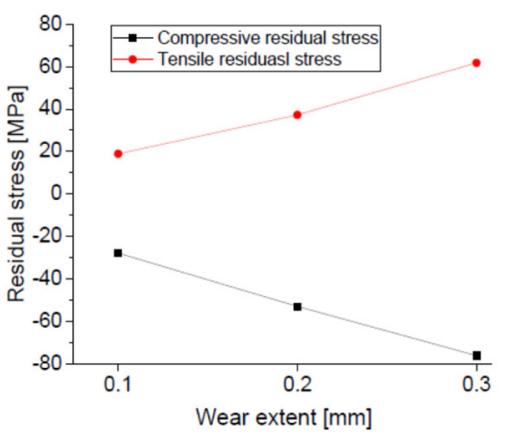

c)

Fig. 16. Maximum residual stress of machined surface with three types of milling cutters; a) VH, b) VP, and c) SD 
loading of the sample was performed from the depth of $0 \mathrm{~nm}$ to $1000 \mathrm{~nm}$; dwelling was executed from 1000 $\mathrm{nm}$ to $1024 \mathrm{~nm}$, and, finally, unloading was done from $1024 \mathrm{~nm}$ to $769 \mathrm{~nm}$. The obtained loading/unloading curve is shown in Fig. 17.

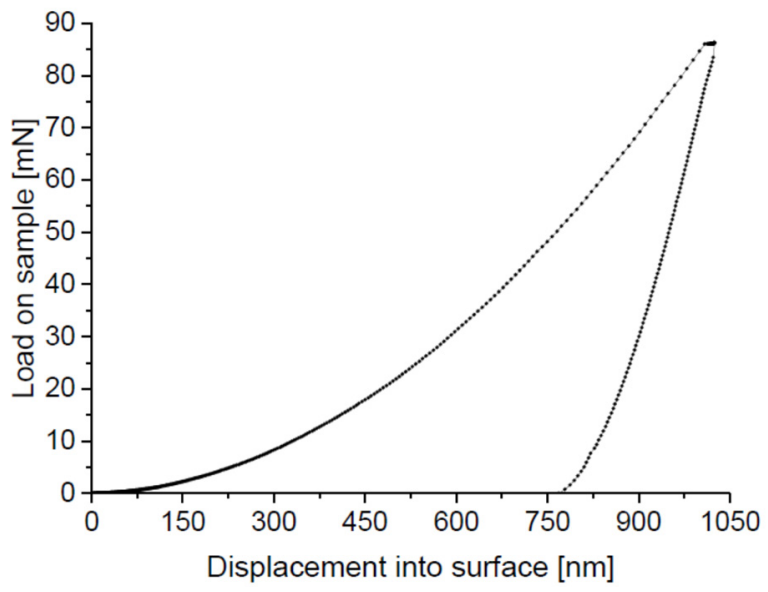

Fig. 17. Loading/unloading curve

As shown in Fig. 18, the sub-surface of nine machined samples were divided into three regions according to the positions of intentions. These were characterized as the hard region, soft region, and near the bulk material region.

Fig. 19 showed the nano hardness in the hard region, soft region, and near bulk material region with the wear from $0.1 \mathrm{~mm}$ to $0.3 \mathrm{~mm}$. The hardness of the material in the hard region was the greatest, followed by the near bulk material region, and the hardness of the material in the soft region was the smallest. It can also be observed that the geometric structure parameters of the three types of milling cutters had little influence on the hardness distribution beneath the machined surface.

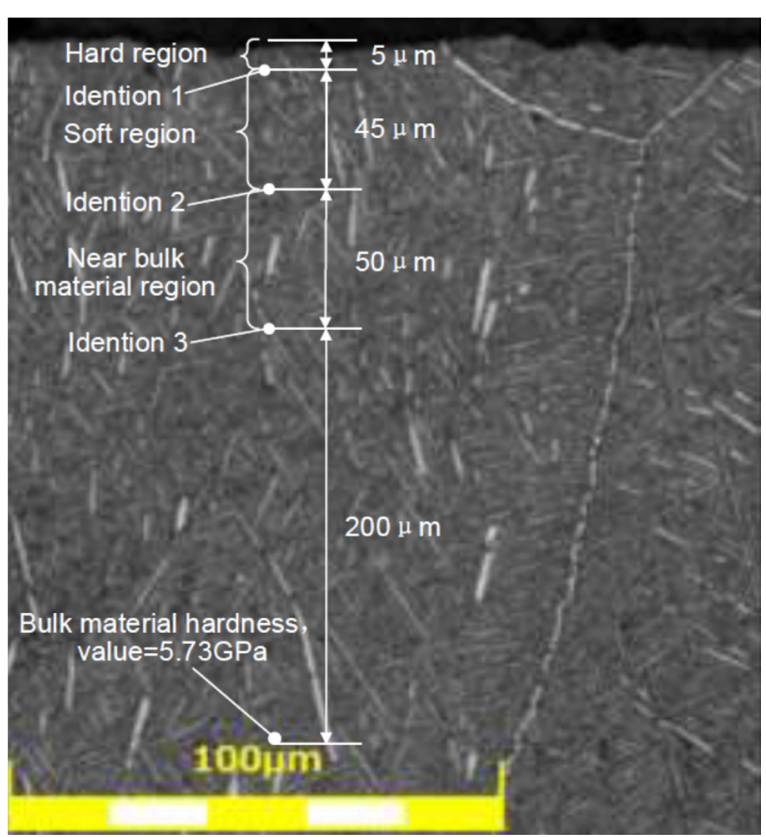

Fig. 18. Regions below the machined surface

During the processing, the titanium elements in the titanium alloy interacted with oxygen elements and nitrogen elements in the air to form titanium oxide and titanium nitride, which made the machined surface brittle [37] and increased the microhardness of the hardening zone. The extrusion pressure on the workpiece surface was also an important reason for the increase of hardness in the hardening zone.

Furthermore, the thermal conductivity of TB6 titanium alloy was low, which caused the cutting heat to be too late to transfer in cutting titanium alloy,

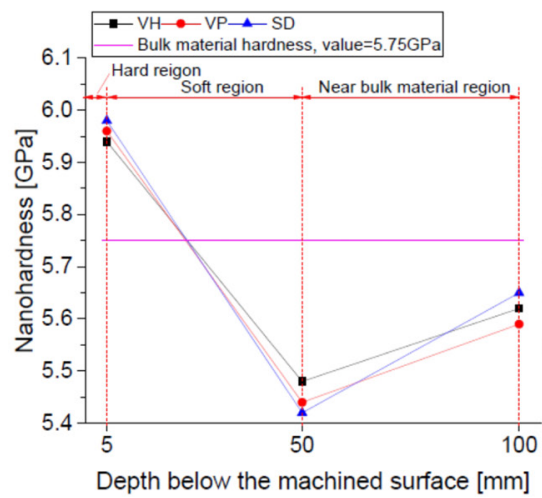

a)

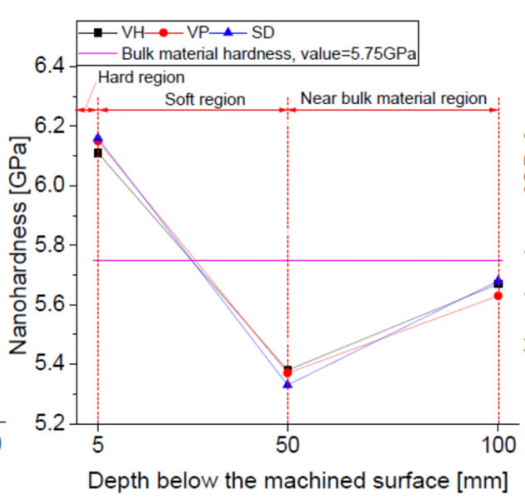

b)

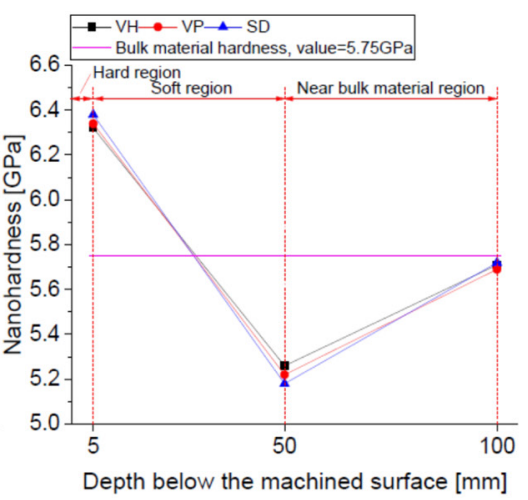

c)

Fig. 19. Hardness of machined surface with three types of milling cutters; a) VB=0.1 mm, b) VB=0.2 $\mathrm{mm}$, and c) VB=0.3 mm 
resulting in thermal expansion, dislocation density reduction, and hardness reduction of the material in the soft region.

Thermal softening also resulted in the expansion of material in the soft region. As a result, the material in the near bulk material region was squeezed, which caused the dislocation density to increase, thereby also causing the hardness of the material in the near bulk material region to increase.

Fig. 20 shows the relationship between wear and microhardness of the three types of milling cutters. It can be observed from the figure that the hardness of the material in the hard region and near the bulk material region increased with the increase of wear, while the hardness of the material in the soft region decreased. It also can be observed that the changes of hardness in the three regions were aggravated with the increase of wear.

Wear further caused the contact area between the flank face of the milling cutter and the workpiece to increase. Then the extrusion pressure increased, resulting in an increase in the microhardness of material in the hard region. Wear also caused the friction between the flank face and the workpiece to increase, thereby causing an increase in the cutting heat, which resulted in the enhancement of the thermal softening effect and the decrease of the hardness of the material in soft region. The enhanced thermal softening effect in the soft region, in turn, led to the aggravation of material expansion, which increased the material extrusion in the near bulk material region to cause an increase the hardness of the material in near bulk material region.

\subsubsection{Microstructure}

As shown in Figs. 21 to 23, surface defects were mainly the tears and cavities, and there was no obvious plastic deformation observed because of the small cutting depths.

To summarize, wear and tool geometry have an important influence on chatter, cutting force, and surface integrity.

Wear of milling cutter can cause increases of chatter, cutting force, roughness, residual stress and microhardness. Wear affects the cutting force coefficient and process damping coefficient [38], which have significant influence on the chatter stability zone in the cutting process, which causes the chatter to increase thereby affecting the roughness

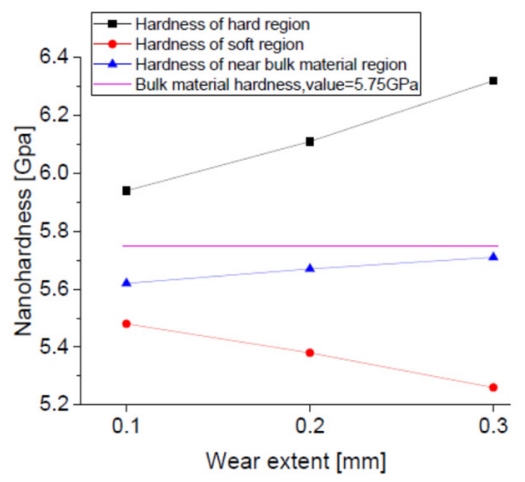

a)

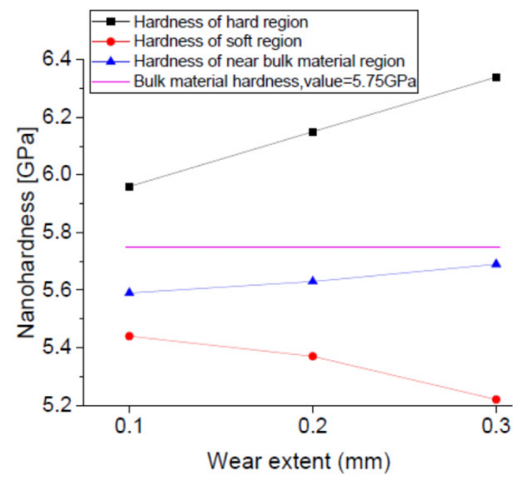

b)

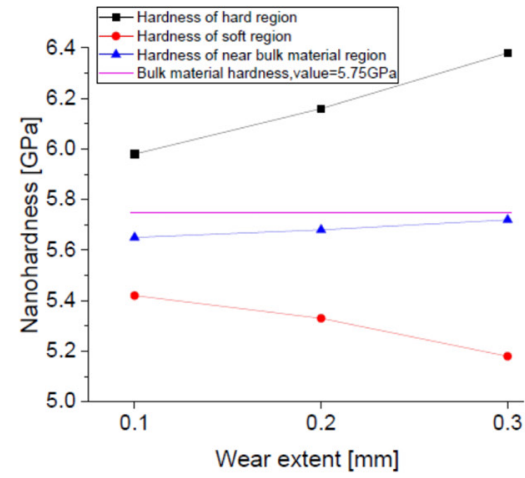

c)

Fig. 20. Influence of wear on hardness with three types of milling cutters; a) $V B=0.1 \mathrm{~mm}, b) \mathrm{VB}=0.2 \mathrm{~mm}$, and c) VB=0.3 $\mathrm{mm}$

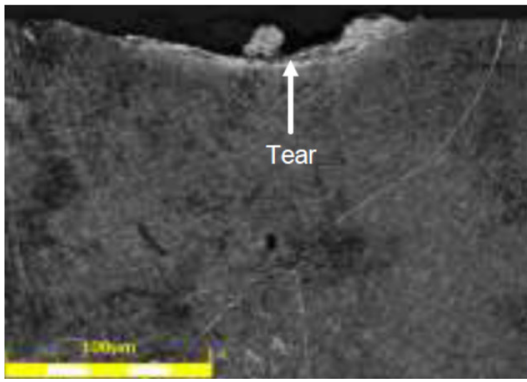

a)

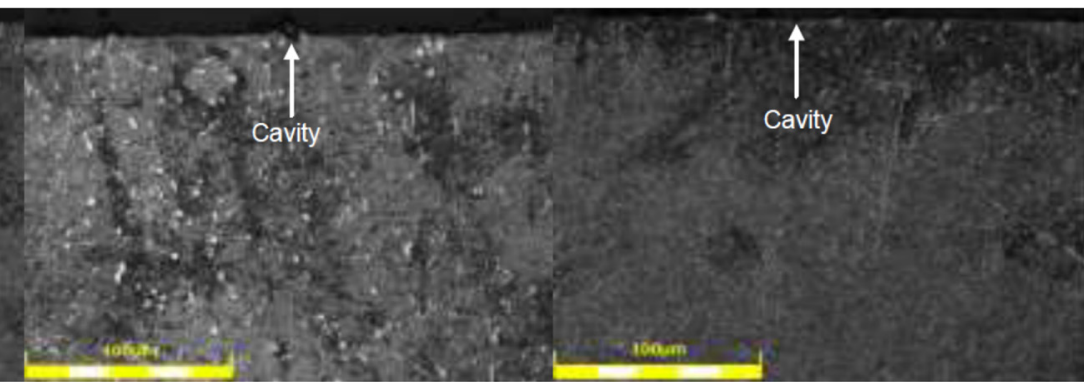

b) c)

Fig. 21. Microstructure of machined surface with VH milling cutter (1000x);a) VB=0.1 mm, b) VB=0.2 mm, and c) VB=0.3 mm 


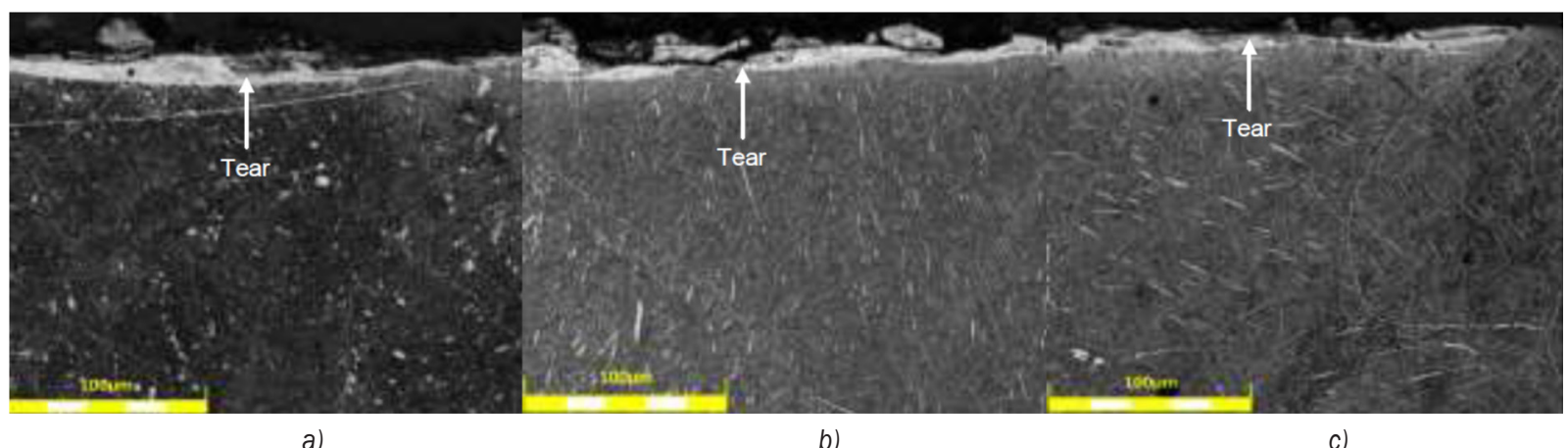

a)

b)

c)

Fig. 22. Microstructure of machined surface with VP milling cutter (1000x);a) VB=0.1 mm, b) VB=0.2 $\mathrm{mm}$, and c) VB=0.3 mm

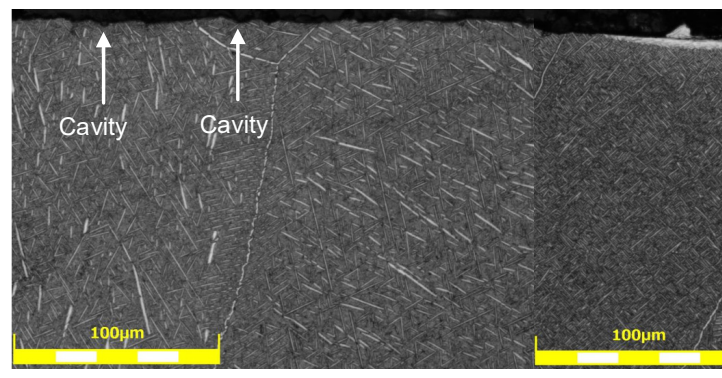

a)

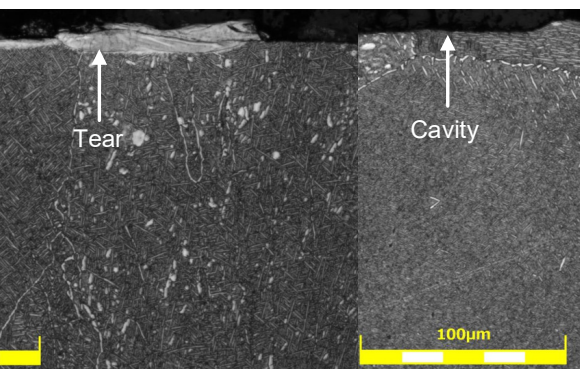

b)

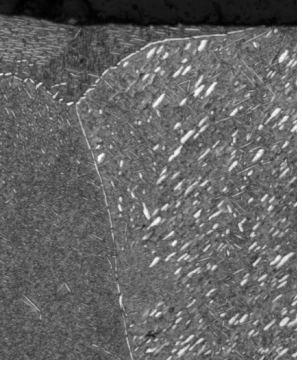

c)

Fig. 23. Microstructure of machined surface with SD milling cutter $(1000 x) ; a) V B=0.1 \mathrm{~mm}, b) \mathrm{VB}=0.2 \mathrm{~mm}$, and c) VB=0.3 mm

of the machined surface. The extrusion pressure and friction on the workpiece surface further increase with the increase in wear, resulting in the increase of cutting force and cutting heat which directly affect the residual stress and microhardness.

Moreover, the geometric structure parameters of milling cutters influence chatter, cutting force and roughness. The change of tooth pitch caused changes in the phase of cutting motion, while changes of the helix angle caused changes in the working rake angle of the milling cutter. These changes affected the periodic change of cutting force and reduced chatter. At the same time, the actual feed change caused by the change of tooth pitch and the change of working rake angle caused by the change of helix angle affected the cutting force and roughness.

\section{CONCLUSIONS}

In this paper, titanium alloy TB6 was dry-machined using three types of milling cutters to investigate the chatter, cutting force and workpiece surface integrity with tool wear. The main results are summarized as follows:

i. Tool geometry had a significant influence on milling cutter wear. Compared with SD milling cutter, the wear of VP and VH milling cutters which had different helixes and pitches, was faster, and changed helix and pitch resulted in uneven wear. Also, with the increase of wear, the wear unevenness of VP and VH milling cutters tended to decrease tendency.

ii. Wear of VP, VH and SD milling cutters had a significant effect on chatter and cutting forces. Chatter and cutting forces increased with the increase of wear for the three types of milling cutters.

iii. The change of tool geometry can effectively suppress the chatter. Compared with the standard milling cutter, the pitch and helix angle of VP and VH milling cutter changed, and the chatter suppression effect of vibration-free milling cutter was found to be better than that of the standard milling cutter.

iv. For VP and VH milling cutters, cutting forces were affected by both tool geometry and wear. Compared with the standard milling cutter, although the changes of helix and pitch affected cutting forces, wear decreased the radial cutting depth while increasing the extrusion pressure, thereby making the cutting force of vibration-free milling cutter the result of these factors.

v. Surface roughness increased with the increase of wear of three types of milling cutters, and 
the roughness produced by $\mathrm{VH}$ and VP milling cutters was smaller than that of SD milling cutter. Residual compressive stress tended to be the main stress with the increase of wear of all the milling cutters. Furthermore, microhardness increased with the increase of the wear of all cutters in the hard region and near the bulk material region, while it decreased with the increase of wear in the soft region.

\section{ACKNOWLEDGEMENTS}

This work was supported by the Beijing Key Laboratory of Digital Design and Manufacturing, Beijing Municipal Education Commission (build a project). The authors would like to express their appreciation to the agency.

\section{REFERENCES}

[1] Bai, J., Bai, Q., Tong, Z., Chen, G. (2018). The influence of cutting parameters on the defect structure of subsurface in orthogonal cutting of titanium alloy. Journal of Materials Research, vol. 33, no. 6, p. 720-732, D0l:10.1557/ jmr.2017.397.

[2] Kolli, R.P., Arun, D. (2018). A review of metastable beta Titanium alloys. Metals, vol. 8, no. 7, p. 506, D0l:10.3390/ met8070506.

[3] Arrazola, P.-J., Garay, A. Iriarte L-M., Armendia, M., Marya, S., Maître, F.L. (2009). Machinability of titanium alloys (Ti6Al4V and Ti555.3). Journal of Materials Processing Technology, vol. 209, no. 5, p. 2223-2230, D0l:10.1016/j. jmatprotec.2008.06.020.

[4] Boyer, R.R., Briggs, R.D. (2005). The use of $\beta$ titanium alloys in the aerospace industry. Journal of Materials Engineering \& Performance, vol. 14, no. 6, p. 681-685, Dol:10.1361/105994905X75448.

[5] Gupta, K., Laubscher, R.F. (2017). Sustainable machining of titanium alloys: A critical review. Proceedings of the Institution of Mechanical Engineers Part B Journal of Engineering Manufacture, vol. 231, no. 14, p. 2543-2560, DOI:10.1177/0954405416634278.

[6] Niknam, S.A., Khettabi, R., Songmene, V. (2014). Machinability and machining of titanium alloys: A review. Machining of Titanium Alloys, p. 1-30, D0l:10.1007/978-3-662-43902-9_1.

[7] Davim, J.P. (ed.) (2010). Surface Integrity in Machining. Springer, London.

[8] Zhao, Q., Qin, X., Ji, C., li, Y., Sun, D., Jin, Y. (2015). Tool life and hole surface integrity studies for hole-making of Ti6Al4V alloy. The International Journal of Advanced Manufacturing Technology, vol. 79, no. 5, p. 1017-1026, Dol:10.1007/ s00170-015-6890-z.

[9] Pimenov, D., Hassui, A., Wojciechowski, S., Mia, M., Magri, A. Suyama, D.I., Bustillo, A., Krolczyk, G., Gupta, M.K. (2019). Effect of the relative position of the face milling tool towards the workpiece on machined surface roughness and milling dynamics. Applied Sciences, vol. 9, no. 5, p. 842, DOl:10.3390/app9050842.

[10] Tobias, S.A. (1965). Machine-Tool Vibration. Wiley, Hoboken.

[11] Tobias, S.A., Fishwick, W. (1958). Theory of regenerative machine tool chatter. Engineer, vol. 205, p. 199-203.

[12] Guo, Q., Jiang, Y. Zhao, B., Ming, P. (2016). Chatter modeling and stability lobes predicting for non-uniform helix tools. International Journal of Advanced Manufacturing Technology, vol. 87, no. 1-4, p. 251-266, Dol:10.1007/s00170-016-8458-y.

[13] Tlusty, J. (1986). Dynamics of High-Speed Milling. ASME Journal of Manufacturing Science and Engineering, vol. 108, no. 2, p. 59-67, DOI:10.1115/1.3187052.

[14] Altintaş, Y., Budak, E. (1995). Analytical prediction of stability lobes in milling. CIRP Annals, vol. 44, no. 1, p. 357-362, D0I:10.1016/S0007-8506(07)62342-7.

[15] Çomak, A., Koca, R., Özkırıml, O., Budak, E. (2013). Modeling and simulation based design of variable pitch and variable helix milling tools for increased chatter stability. $7^{\text {th }}$ International Conference and Exhibition on Design and Production of Machines and Dies/Molds.

[16] Yue, C., Gao, H., Liu, X., Liang, S.Y., Wang, L. (2019). A review of chatter vibration research in milling. Chinese Journal of Aeronautics, vol. 32, no. 2, p. 215-242, Dol:10.1016/j. cja.2018.11.007.

[17] Otto, A., Rauh, S., Ihlenfeldt, S., Radons, G. (2017). Stability of milling with non-uniform pitch and variable helix tools. International Journal of Advanced Manufacturing Technology, vol. 89, no. 9, p. 2613-2625, Dol:10.1007/s00170-016-97622.

[18] Sims, N.D., Mann, B., Huyanan, S. (2008). Analytical prediction of chatter stability for variable pitch and variable helix milling tools. Journal of Sound and Vibration, vol. 317, no. 3-5, p. 664-686, D0I:10.1016/j.jsv.2008.03.045.

[19] Wang, Y., Wang, T., Yu, Z., Zhang, Y., Wang, Y., Liu, H. (2015). Chatter prediction for variable pitch and variable helix milling. Shock and Vibration, vol. 2015, art. ID 419172, DOI:10.1155/2015/419172.

[20] Altintas, Y., Engin, S., Budak, E. (1999). Analytical stability prediction and design of variable pitch cutters. Journal of Manufacturing Science and Engineering, vol. 121, no. 2, p. 173-178, Dol:10.1115/1.2831201.

[21] Li, H., Zheng, H., Tang L. (2010). Theoretical and experimental investigation of the effects of an irregular-pitch cutter on vibration in face-milling. Journal of Mechanical Science and Technology, vol. 24, no. 11, p. 2169-2174, D0l:10.1007/ s12206-010-0818-1.

[22] Niu, J., Ding, Y., Zhu, L., Ding, H. (2017). Mechanics and multiregenerative stability of variable pitch and variable helix milling tools considering runout. International Journal of Machine Tools \& Manufacture, vol. 123, p. 129-145, D0l:10.1016/j. ijmachtools.2017.08.006.

[23] Ikua, B.W., Tanaka, H., Obata, F., Sakamto, S. (2001). Prediction of cutting forces and machining error in ball end milling of curved surfaces-I theoretical analysis. Precision Engineering, vol. 25, no. 4, p. 266-273, Dol:10.1016/S01416359(01)00077-0.

[24] Toh, C.K. (2004). A study of the effects of cutter path strategies and orientations in milling. Journal of Materials Processing 
Technology, vol. 152, no. 3, p. 346-356, D0l:10.1016/j. jmatprotec.2004.04.382.

[25] Huang, P., Li, J., Sun, J., Zhou, J. (2013). Study on vibration reduction mechanism of variable pitch end mill and cutting performance in milling titanium alloy. International Journal of Advanced Manufacturing Technology, vol. 67, no. 5-8, p. 1385-1391, D0I:10.1007/s00170-012-4575-4.

[26] Liang, X., Liu, Z. (2017). Experimental investigations on effects of tool flank wear on surface integrity during orthogonal dry cutting of Ti-6Al-4V. International Journal of Advanced Manufacturing Technology, vol. 93, no. 5-8, p. 1617-1626, D0l:10.1007/s00170-017-0654-x.

[27] Yang, H., Chen, Z., Zhou, Z. (2015). Influence of cutting speed and tool wear on the surface integrity of the titanium alloy Ti-1023 during milling. International Journal of Advanced Manufacturing Technology, vol. 78, no. 5-8, p. 1113-1126, D0l:10.1007/s00170-014-6593-x.

[28] Sharman, A.R.C., Hughes, J.I., Ridgway, K. (2006). An analysis of the residual stresses generated in Inconel $718^{\mathrm{TM}}$ when turning. Journal of Materials Processing Technology, vol. 173, no. 3, p. 359-367, D0l:10.1016/J.jmatprotec.2005.12.007.

[29] Chen, L., El-Wardany, T.I., Harris, W.C. (2004). Modelling the effects of flank wear land and chip formation on residual stresses. CIRP Annals, vol. 53, no. 1, p. 95-98, D0l:10.1016/ S0007-8506(07)60653-2.

[30] Sharman, A.R.C., Hughes, J.I., Ridgway, K. (2004). workpiece surface integrity and tool life issues when turning inconel $718^{\mathrm{TM}}$ nickel based superalloy. Machining Science \& Technology, vol. 8, no. 3, p. 399-414, D0l:10.1081/MST-200039865.
[31] Sadat, A.B., Reddy, MY. (1992). Surface integrity of inconel-718 nickel-base superalloy using controlled and natural contact length tools. Part I: Lubricated. Experimental Mechanics, vol. 32, no. 3, p. 282-288, D0l:10.1007/BF02319367.

[32] Editorial (2002). China Aeronautical Materials Handbook. China Standard Press, Beijing, p. 253-273. (in Chinese)

[33] Toh, C.K. (2004). Vibration analysis in high speed rough and finish milling hardened steel. Journal of Sound \& Vibration, vol. 278, no. 1-2, p. 101-115, D0l:10.1016/j.jsv.2003.11.012.

[34] Yuan, N., Rahman, M., Wong, Y.S. (2000). Monitoring of chatter in high speed end-milling using audio signals method. Proceedings of the $33^{\text {rd }}$ International MATADOR Conference. Springer, London, p. 421-426, D0l:10.1007/978-1-4471-07774_65.

[35] Liu, J., Qiao, L., Chen, W. (2019). Wear analysis in machining of tb6 titanium alloy with vibration-free milling cutter. Tool Engineering, vol. 10, p. 13-17.

[36] Liu, J., Sun, J., Chen, W. (2017). Surface integrity of TB6 titanium alloy after dry milling with solid carbide cutters of different geometry. International Journal of Advanced Manufacturing Technology, vol. 92, no. 3, p. 4183-4198, DOI:10.1007/s00170-017-0417-8.

[37] Usui (1982). Cutting and Grinding Process, Beijing, vol. 12, p. 58-85. (in Chinese)

[38] Liu, Y., Wang, Z.Y., Liu, K., Zhang, Y. (2017). Chatter stability prediction in milling using time-varying uncertainties. International Journal of Advanced Manufacturing Technology, vol. 89, no. 9-12, p. 2627-2636, D0l:10.1007/s00170-0169856-x. 